\title{
How Can We Manage Gallbladder Lesions by Transabdominal Ultrasound?
}

\author{
Shinji Okaniwa (D)
}

Citation: Okaniwa, S. How Can We Manage Gallbladder Lesions by Transabdominal Ultrasound? Diagnostics 2021, 11, 784. https://doi.org/ 10.3390/diagnostics11050784

Academic Editor:

Masataka Kikuyama

Received: 23 March 2021

Accepted: 24 April 2021

Published: 26 April 2021

Publisher's Note: MDPI stays neutral with regard to jurisdictional claims in published maps and institutional affiliations.

Copyright: (C) 2021 by the author. Licensee MDPI, Basel, Switzerland. This article is an open access article distributed under the terms and conditions of the Creative Commons Attribution (CC BY) license (https:// creativecommons.org/licenses/by/ $4.0 /)$.
Department of Gastroenterology, Iida Municipal Hospital 1, Iida, Nagano 395-8502, Japan; okaniwa@cocoa.ocn.ne.jp; Tel.: +81-265-21-1255; Fax: +81-265-21-1266

\begin{abstract}
The most important role of ultrasound (US) in the management of gallbladder (GB) lesions is to detect lesions earlier and differentiate them from GB carcinoma (GBC). To avoid overlooking lesions, postural changes and high-frequency transducers with magnified images should be employed. GB lesions are divided into polypoid lesions (GPLs) and wall thickening (GWT). For GPLs, classification into pedunculated and sessile types should be done first. This classification is useful not only for the differential diagnosis but also for the depth diagnosis, as pedunculated carcinomas are confined to the mucosa. Both rapid GB wall blood flow (GWBF) and the irregularity of color signal patterns on Doppler imaging, and heterogeneous enhancement in the venous phase on contrastenhanced ultrasound (CEUS) suggest GBC. Since GWT occurs in various conditions, subdividing into diffuse and focal forms is important. Unlike diffuse GWT, focal GWT is specific for GB and has a higher incidence of GBC. The discontinuity and irregularity of the innermost hyperechoic layer and irregular or disrupted GB wall layer structure suggest GBC. Rapid GWBF is also useful for the diagnosis of wall-thickened type GBC and pancreaticobiliary maljunction. Detailed B-mode evaluation using high-frequency transducers, combined with Doppler imaging and CEUS, enables a more accurate diagnosis.
\end{abstract}

Keywords: gallbladder carcinoma; ultrasound (US); differential diagnosis; polypoid lesion; wall thickening; high-resolution US (HRUS); color Doppler imaging; contrast-enhanced US (CEUS); high-frequency transducer

\section{Introduction}

As ultrasound (US) is a simple and noninvasive procedure without radiation exposure, it is widely used for cancer screening and health checkups [1,2]. Both gallbladder (GB) polypoid lesions (GPLs) and wall thickening (GWT) are common US findings, and GB carcinomas (GBCs) are also detected incidentally in patients with no symptoms. According to the systematic review, malignant GPLs had an incidence of just $0.57 \%$ [3].

The management of GB lesions can be divided into detection, differentiation, and evaluation of extension. GBC is often diagnosed at an advanced stage because of being asymptomatic in early stages, its aggressive nature, and its ability to spread rapidly. However, the detection and resection rate for GBC in the mass screening of 204,099 persons is $0.040 \%$ (81 cases) and $88 \%$, respectively [2], and US can depict $55 \%$ or more of GBC as tumors [4]. Thus, US is recommended as the first step modality for patients with suspicion of GB abnormalities [5,6], including cholelithiasis, inflammation, and malignancy.

However, the sensitivity and accuracy of US are highly dependent on the diagnostic skill of sonographers and conditions of patients. In addition, both detection and differentiation of lesions become more challenging in complicated conditions of GB, such as acute and chronic inflammation and inclusion of stones or debris.

This review classifies various GB lesions according to their US appearance and reviews the current status of differential diagnosis by US findings. 


\section{Tips for GB Evaluation}

The GB is an elliptical or pear-shaped sac-like organ attached to the inferior surface of the liver and easily changes its shape with food intake and postural position, which makes it difficult to visualize the entire GB. To avoid overlooking lesions, especially in the neck and fundus, postural changes such as left lateral decubitus or sitting position should add to ordinal supine imaging (Figure 1). Furthermore, applying the probe diagonally to the abdominal wall can manage reverberations that obscure lesions in the fundus [7]. It is also effective to adopt a shallow depth (about 6-8 cm) or employ a zoom magnification sufficient to recognize the whole GB, to pick up small lesions that are difficult to detect with a normal depth of field $(12-14 \mathrm{~cm})$.

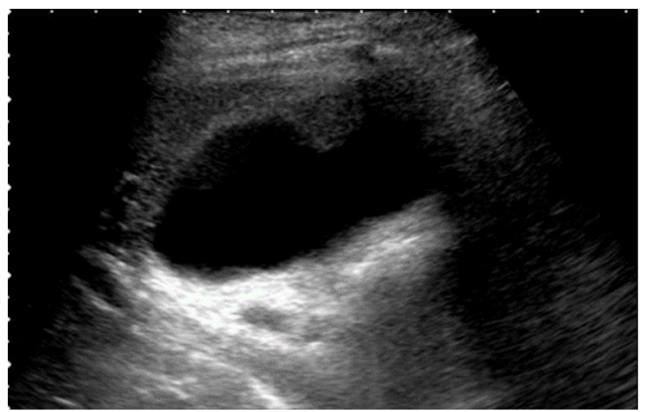

(a)

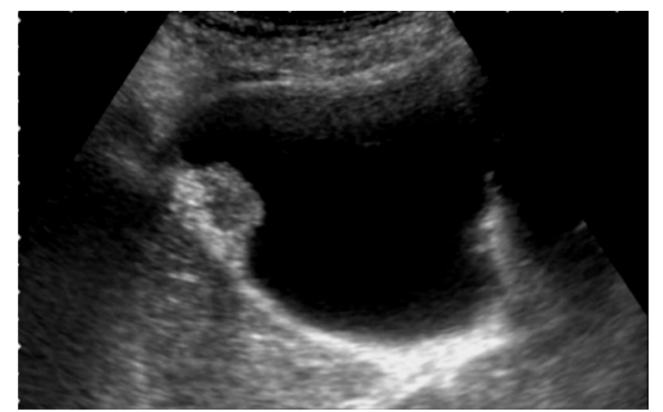

(b)

Figure 1. Alteration of US images with postural changes. In the supine position, GBC in the fundus was obscured by reverberation artifacts (a), but a high-frequency probe can delineate the GBC in the left lateral decubitus position (b).

Compared with low-frequency transducers $(2-5 \mathrm{MHz})$, which are usually employed in routine US, high-frequency transducers $(5-7 \mathrm{MHz})$ provide excellent images of the internal structure of GPLs [7], but penetration tends to be shallow. However, recent advances in US technology have allowed high-frequency transducers to provide resolutions of greater than $8 \mathrm{~cm}$, which can cover the entire GB. High-frequency transducers can also delineate the GB wall as a two- or three-layer structure: The inner hypoechoic layer and outer hyperechoic layer or hyperechoic inner and outer layers, and a hypoechoic middle layer.

High-resolution US (HRUS) is a useful technique, in particular for detecting small lesions, which use both low- and high-frequency transducers during evaluation [8]. Kim et al. [8] reported that the sensitivity and specificity for diagnosing malignant polyps using HRUS were $66.6 \%$ and $89.2 \%$, respectively. Joo et al. [9] showed that HRUS can be helpful for distinguishing adenomyomatosis (ADM) from early-stage wall-thickening-type GBCs. Therefore, for differential diagnosis, additional detailed evaluation with magnified images using high-frequency convex and linear transducers is essential (Figure 2).

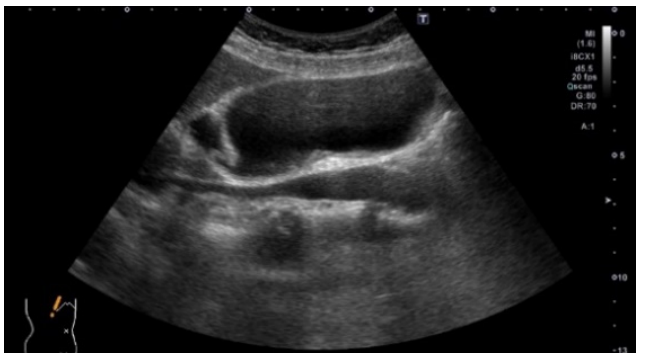

(a)

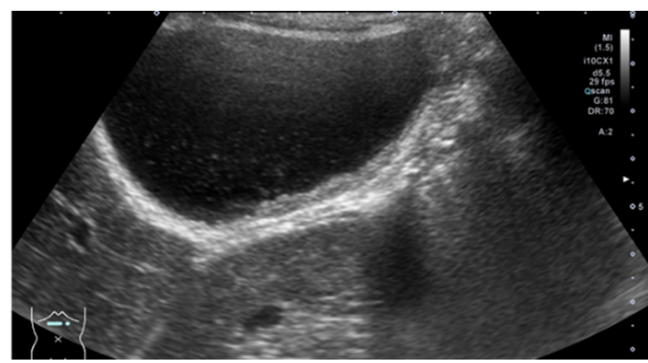

(b)

Figure 2. Evaluation of GB using a HRUS technique. Compared with an image of routine US (a), localized slight thickening of an inner hypoechoic layer was clearly shown in the magnified image using a high-frequency transducer (b) (GBC case). 


\section{Morphological Classification of US Appearance}

US appearance of GB lesions is broadly divided into polypoid lesions (GPLs) and wall thickening (GWTs) (Figure 3). This classification is useful for differential diagnosis and is also used in US cancer screening [1].

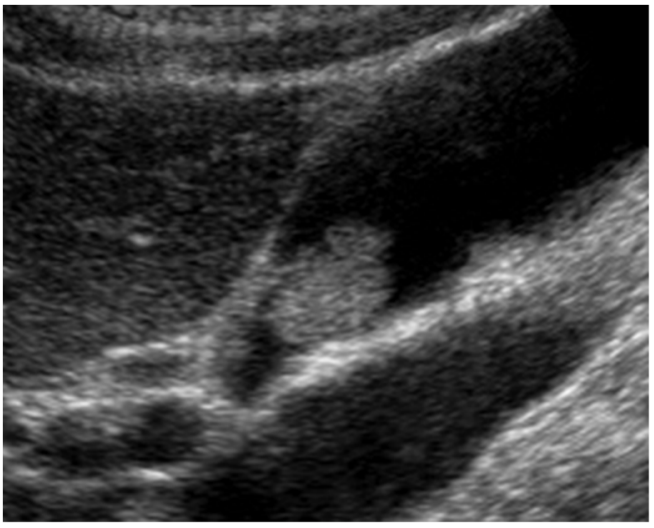

(a)

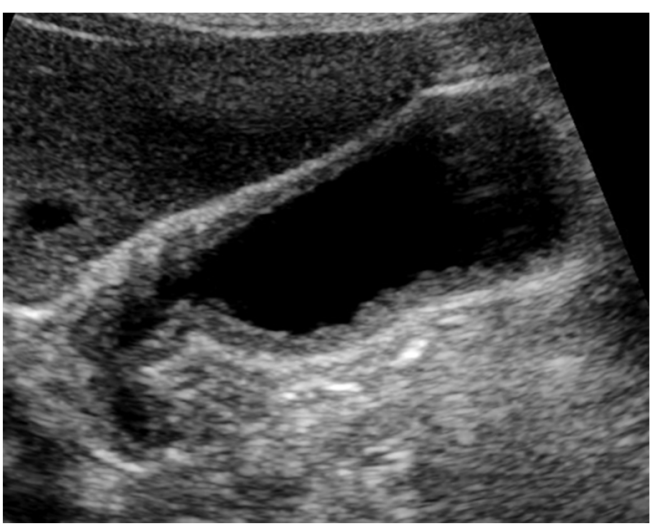

(c)

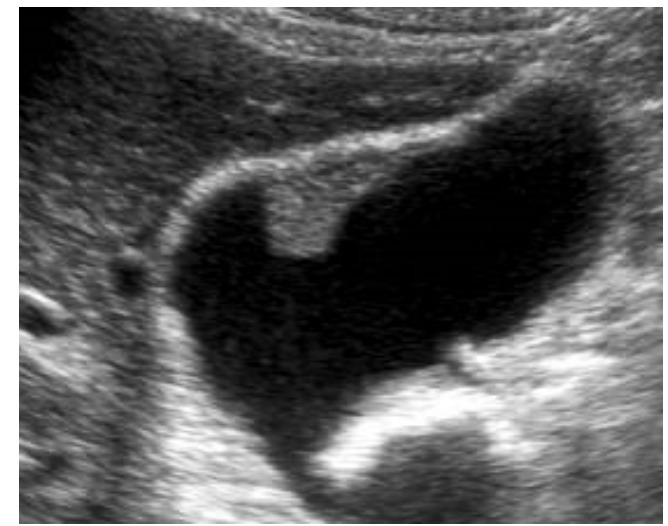

(b)

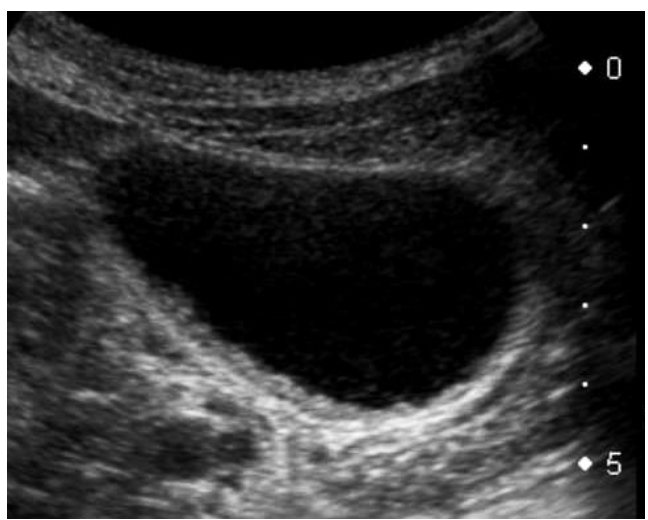

(d)

Figure 3. Morphological classification of US appearance. (a) Pedunculated GPL, (b) sessile (broadbased) GPL, (c) diffuse GWT, (d) focal GWT (all cases are GBCs).

GPLs are defined as focal elevation or protrusions that are distinguishable from the surrounding mucosa, and can be classified into pedunculated and sessile (broad-based). This classification is useful not only for the differential diagnosis, but also for assessing the depth of invasion. Pedunculated carcinomas are considered to be confined to the mucosal layer (M) [10-12]. However, sessile (broad-based) carcinomas include early-stage cancers as well as advanced cancers that invade deeper than the subserosa (SS). The most important targets to be differentiated are cholesterol polyps in the pedunculated type and adenomyomatosis (ADM) in the sessile type. For GPLs that are difficult to classify, it is recommended to check for polyp shape change due to postural changes. In addition, contrast-enhanced US (CEUS) can accurately diagnose pedunculated lesions, which showed a sessile shape on the conventional B-mode (pseudo-sessile-shaped polyp) [13]. Three-dimensional US can also facilitate the morphological recognition of GPLs [14]. If the classification is still difficult, the lesion should be classified as sessile with a high frequency of malignant lesions.

GWTs should be determined as wall thickening of $4 \mathrm{~mm}$ or more, and subdivided into diffuse and focal [1]. The presence of a partial inner hypoechoic layer of less than $4 \mathrm{~mm}$ in thickness (Figure 4) should also be included in focal GWT [1], as it may correspond to earlystage wall-thickening GBC. Diffuse GWT is not a specific US finding for GB abnormalities such as cholecystitis and GBCs; it can also occur in systemic diseases or inflammation of organs adjacent to the GB. However, focal GWT is a specific finding for the GB and is 
associated with a high frequency of malignant lesions. As GWTs, especially focal lesions, are more difficult to pick up than GPLs, magnification with a high-frequency transducer is strongly recommended (Figure 2). In addition, US evaluation should be performed after appropriate fasting time to rule out the effect of the postprandial contraction.

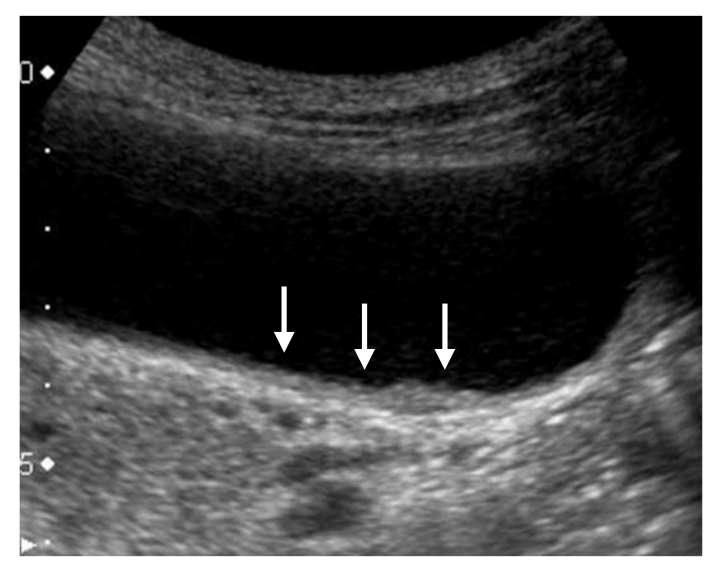

Figure 4. Focal presence of an inner hypoechoic layer (focal GWT). A high-frequency transducer with magnified image showed a slightly thickened inner hypoechoic layer less than 4-mm thick (arrow) in the fundus of GB (GBC case).

\section{Differentiation of GB Polypoid Lesions (GPLs)}

Classification into pedunculated and sessile (broad-based) types (Figure $3 a, b$ ) is essential for differential diagnosis and assessment of the depth of invasion. Pedunculated lesions include the most common cholesterol polyps, early GBCs, adenomas, inflammatory polyps, and hyperplastic polyps. However, sessile lesions include early GBCs, advanced GBCs, localized ADM, and sludge. Sessile shape is a strong predictive factor of GBCs [15-19] and includes both early-stage and advanced GBCs, whereas GBCs are less frequent in pedunculated GPLs and all cases are confined to the mucosal layer [10-12]. According to a systematic review [17], the odds of malignancy in sessile GPLs are increased by a factor of 7.32 (95\% confidence interval 4.18-12.82). In GPLs more than $10 \mathrm{~mm}$, sessile shape (OR, 9.485-41.257) was a significant predictor of differentiating GBCs from adenomas $(p<0.05)[18]$.

This classification is useful for differential diagnosis and has been adopted for US cancer screening [1]. However, since most previous reports have evaluated GPLs without separating pedunculated and sessile lesions, this review also discusses the findings of GPL including both types, except for a few findings.

\subsection{Multiplicity}

The distribution of single polyps has been reported to be 50.7-89.5\% [3], and several studies have reported that a solitary lesion is a common US finding for neoplastic polyps [8,15-19]. A study using cholecystectomy specimens showed that only $25 \%$ of cholesterol polyps were solitary, compared to $88 \%$ of adenomas and GBCs [15]. Solitary polyps are associated with a 2.05 -fold (95\% confidence interval 1.52-2.75) increased probability of malignancy in a systematic review [17]. In addition, in GPLs larger than $10 \mathrm{~mm}$, a single polyp (OR, 3.680-3.856) was also associated with neoplastic polyps $(p<0.05)$ [18].

\subsection{Size}

The size of pedunculated GPLs has been divided into $5 \mathrm{~mm}$ or less than $5 \mathrm{~mm}$, 6-10 $\mathrm{mm}$, and more than $10 \mathrm{~mm}$ for differential diagnosis in US cancer screening [1], and the distribution of GPLs has been reported to be $50 \%, 16.4-42.1 \%$, and $0-2.3 \%$, respectively [3]. Several previous studies have reported that the size of GPLs is deemed a predictive US finding for malignant potential [8,15-21]. This finding was first reported by 
Kozuka et al. [20], who determined that a final pathological size of $12 \mathrm{~mm}$ could separate benign adenomas from adenomas with malignant changes and invasive GBCs. Kubota et al. [15] reported that the mean sizes of cholesterol polyps, adenomas, carcinomas, and inflammatory polyps of cholecystectomy specimens were $8.8,6.9,25.7$, and $4 \mathrm{~mm}$, respectively. These data suggest that a size of $10 \mathrm{~mm}$ can be used for the differential diagnosis. However, even polyps smaller than $10 \mathrm{~mm}$ can be malignant [19], and most polyps larger than $10 \mathrm{~mm}$ are also benign.

Some current guidelines recommend cholecystectomy for GPLs that are $10 \mathrm{~mm}$ or larger than $10 \mathrm{~mm}$. Park et al. [21] calculated the AUC using the ROC curve to validate the conventional size criteria. The sensitivity and specificity for predicting malignant polyps were $98.2 \%$ and $19.6 \%$ at $10 \mathrm{~mm}$ and $91.0 \%$ and $71.8 \%$ at $13 \mathrm{~mm}$, respectively. Since GPLs in the size range of 10-12 mm were unlikely to be malignant, surgical indication for GPLs larger than $13 \mathrm{~mm}$ can prevent $50 \%$ of unnecessary cholecystectomies without the risk of missing malignant GPLs. According to a clinicopathological study [22], 90\% of polyps $10 \mathrm{~mm}$ or larger than $10 \mathrm{~mm}$ in size are neoplastic. However, since $30 \%$ of neoplastic polyps are smaller than $10 \mathrm{~mm}$, even small polyps need to be carefully monitored, especially in elderly patients.

Regarding the growth rate, the percentage of GPLs that showed growth over the follow-up period ranged from $1 \%$ to $23 \%$ [19]. Kubota et al. [15] reported that all GPLs with an increase in maximum diameter (1.5-4 times over 4-12 months) were GBCs. Although it is difficult to find a specific growth rate that suggests an increased risk of malignancy, a rapid change in size should raise the suspicion of malignancy. An initial review within 6 months is recommended to assess polyp growth.

\subsection{Surface Contour}

Understanding the pathological features is important in interpreting US images of GPLs. According to a pathological study, a nodular surface contour with relatively shallow notches is characteristic of neoplasms, while granular components with relatively deep notches suggest non-neoplastic GPLs [23]. Kim et al. [8] divided the surface contour of GPLs into smooth and lobulated types using HRUS and found that the smooth surface was significantly common in non-neoplastic polyps and lobulated surface was significantly common in neoplastic polyps. Choi et al. [24] also divided the polyp surface into lobulated and non-lobulated using endoscopic ultrasound (EUS), and reported that lobulated surface structures were more common in neoplastic lesions in both univariate $(p<0.01)$ and multivariate analyses $(p=0.03)$. Based on these reports, nodular or lobulated patterns should be considered neoplastic. However, Sugiyama et al. [25] examined the surface of cholesterol polyps by size and reported that the surface of $10 \mathrm{~mm}$ or smaller cholesterol polyps showed smooth $(55.9 \%)$, granular $(35.3 \%)$, or nodular patterns $(8.8 \%)$, while the polyp surface larger than $10 \mathrm{~mm}$ was granular $(85.7 \%$.), smooth $(7.2 \%)$, or nodular $(7.2 \%)$. Thus, the sensitivity of smooth pattern for non-neoplastic GPLs depended on size, and the outline of GPLs within 11-20 mm could not distinguish between malignant and benign GPLs [13].

\subsection{Internal Structure}

\subsubsection{Hyperechoic Spots and Aggregation of Echogenic Spots (Mulberry Echo Pattern)}

Most cholesterol polyps are accompanied by a tiny hyperechoic spot or aggregation of echogenic spots (mulberry echo pattern) (Figure 5) [8,18,24-27], which represent a mass of foamy histiocytes containing cholesterol. As both findings showed high specificity (100\%) for cholesterol polyps [26], these findings are considered benign US findings in polyps of 6-10 $\mathrm{mm}$ in size in US cancer screening [1]. However, US only detected these findings in $60-77.1 \%$ of cholesterol polyps $[25,26]$. Since a tiny hyperechoic spot was more common in $10 \mathrm{~mm}$ or smaller cholesterol [25], the presence of a hyperechoic spot could not distinguish between malignant and benign GPLs within 11 to $20 \mathrm{~mm}$ [13]. Furthermore, there is some possibility that neoplastic polyps associated with cholesterolosis were more 
common than we expected [24,28]. Thus, hyperechoic spots alone may not be predictive of cholesterol polyps. Sadamoto et al. [27] proposed a scoring system formula using the maximum diameter, internal echo patterns and hyperechoic spots. The sensitivity and specificity at a cut-off score of more than 12 were $77.8 \%$ and $82.7 \%$, respectively.

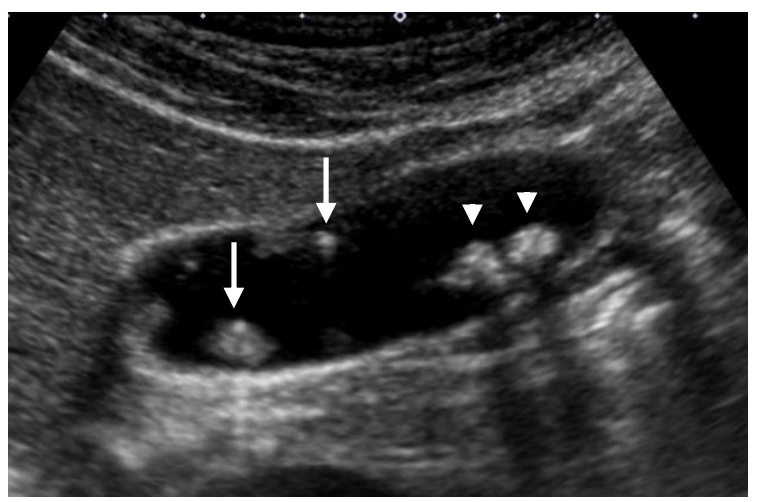

Figure 5. Hyperechoic spots and aggregations of echogenic spots (mulberry echo pattern). A highfrequency transducer depicted hyperechoic spots (arrow) and aggregations of echogenic spots with acoustic shadow (arrowhead) (cholesterol polyps).

\subsubsection{Cystic Structures (Anechoic Spots), Comet Tail Artifacts, Echogenic Foci}

Cystic structures (anechoic spots) reflect two distinct pathological abnormalities: Dilated atypical (neoplastic) glands, especially in well-differentiated GBCs [7,29-31], and Rokitansky-Aschoff sinuses (RAS) in ADMs. High-frequency transducers, especially linear probes with a magnified image, can more precisely delineate these internal structures [7].

Niizawa et al. [29] were the first to report small anechoic spots in adenomas corresponding to dilated ductal structures. Noda et al. [30] also reported that cystic lesions about $2 \mathrm{~mm}$ in size were observed in $63.6 \%$ of adenomas, which histologically corresponded to cystically dilated atypical glands. These lesions, unlike RAS, appear as irregularly shaped and unequal sized cystic lesions (Figure 6). Yoshimitsu et al. [31] reported well-differentiated GBCs with intratumoral cystic components due to abundant mucin production using MRI. They suggested that RAS in ADM was larger in number, round in shape, and aligned in a linear fashion, whereas cystic components of GBCs were multilobulated in shape, larger in size, and had an irregular surface.

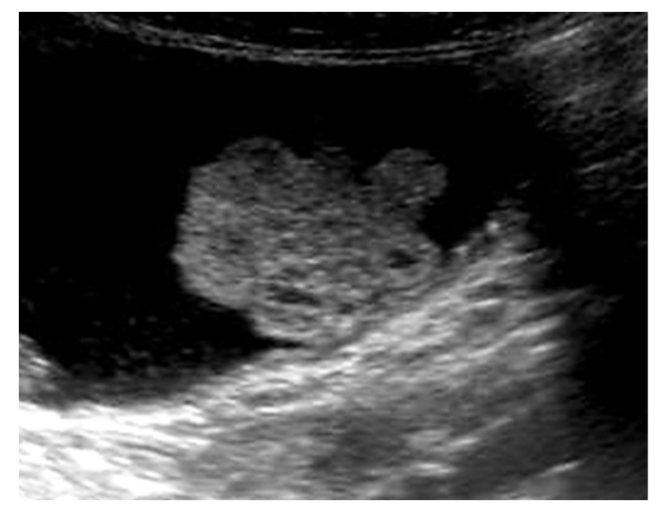

(a)

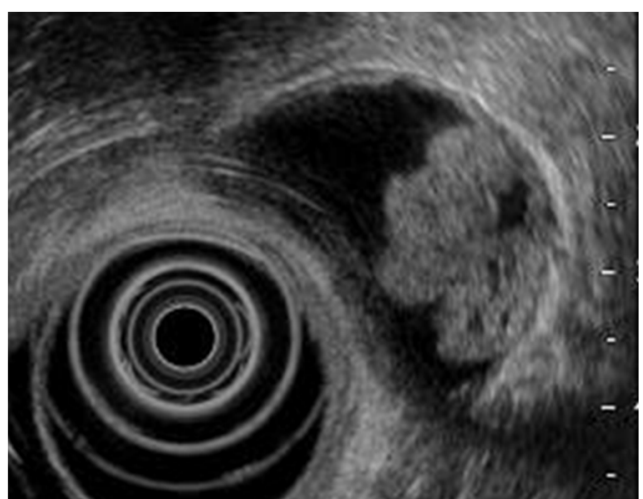

(b)

Figure 6. Cystic structures (anechoic spots) corresponding to cystically dilated cancerous glands. (a) High-frequency transducer $(8 \mathrm{MHz})$ and (b) EUS (12 MHz) showed irregularly shaped cystic lesions of various sizes corresponding to cystically dilated cancerous glands (GBC concomitant with pancreatobiliary maljunction case). 
In ADM, multiple microcystic components correspond to proliferated RAS [32], which is considered a highly specific finding [26,33]. However, the sonographic appearance of cystic lesions varies depending on their size, location, and contents, and the diagnostic accuracy of conventional US has been reported as less than 70\% [34]. In addition to cystic structures, comet-tail artifacts and echogenic foci, which also represent minute cystic lesions and intramural calculus inside RAS are also useful [26]. Furthermore, twinkling artifacts on Doppler image facilitate the detection of RAS containing tiny echogenic foci that commonly cause a reverberation artifact.

CEUS can detect RAS better than conventional US, because RAS remains anechoic while the GB wall is enhanced (Figure 7). Tang et al. [35] reported that a small nonenhancement space observed in both arterial and venous phases was a characteristic finding of ADM, and CEUS (100\%) could increase the degree of visualization of RAS compared with conventional US (67\%). Yuan et al. [36] reported that intramural anechoic space was detected in $56.1 \%$ of focal ADM in contrast to $20.6 \%$ of GBC ( $p=0.002)$.

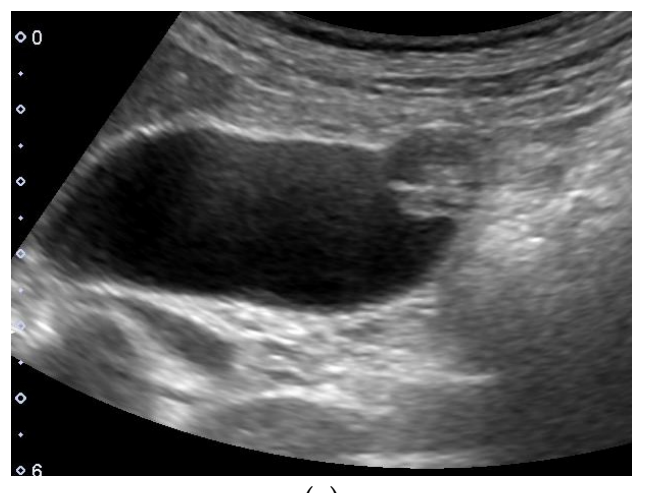

(a)

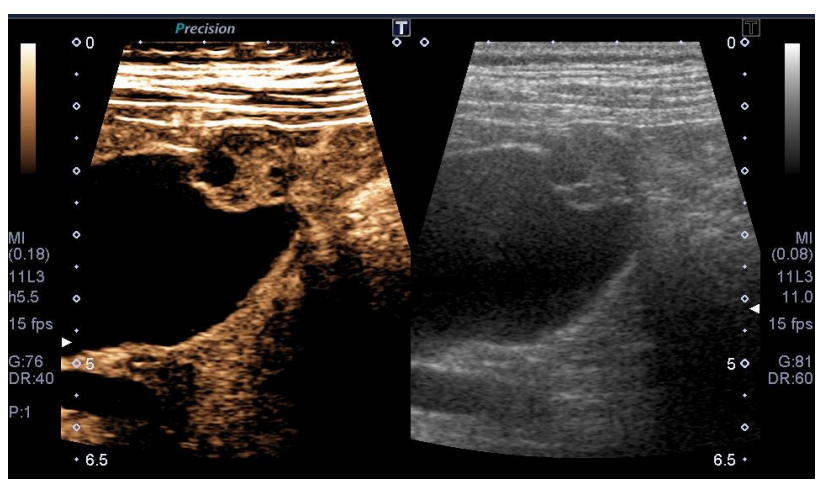

(b)

Figure 7. Cystic structures (anechoic spots) corresponding to RAS. Compared to the conventional US (a), CEUS clearly depicted cystic structures inside the fundal ADM (b).

Recently, several GBCs concomitant with fundal type ADM have been reported [7,35,37-41] (Figure 8). These GBCs showed well-circumscribed papillary growth just above the surface mucosa of ADM or inside RAS. Therefore, even in cases with the presence of RAS, the mucosal surface of ADM and inside RAS should be evaluated in detail to detect concomitant GBCs. Tang et al. [35] reported that the discontinuity of the wall on CEUS was helpful for the diagnosis of ADM with GBC.

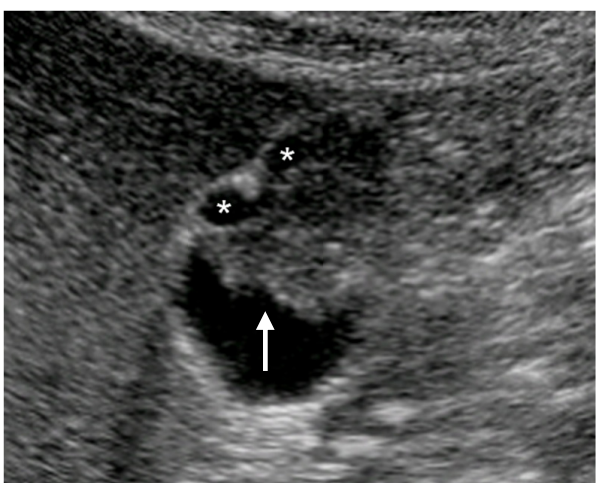

(a)

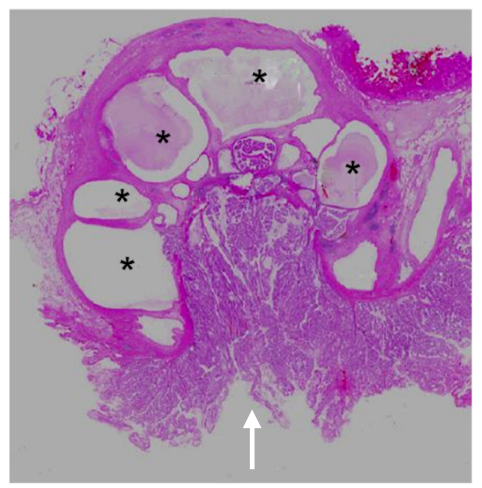

(b)

Figure 8. GBC concomitant with localized ADM. (a) US showed a papillary GPL (arrow) with dilated cystic lesions in the fundus. (b) Histopathologically, a papillary GBC (arrow) arose in the surface mucosa of localized ADM and cystic lesions were corresponding to dilated RASs (*: dilated RAS). Reprinted with permission from ref. [7]. Copyright 2021 Japan Society of Ultrasonics in Medicine. 


\subsection{Stalk Width}

In pedunculated GPLs, the stalk width is another useful finding. Cholesterol polyps usually present with a "ball on the wall sign" [42] because their stalks are thin and cannot be detected by conventional US. The "flickering sign", which is due to the pulsation of vena cava is also a characteristic finding of pedunculated GPLs with a thin stalk and suggestive of cholesterol polyps [7]. Recently, a highly sensitive Doppler imaging modality (superb microvascular imaging (SMI) in the Aplio series (Canon Medical Systems, Otawara, Japan) and B-flow (GE Healthcare, Ltd., Chicago, IL, USA)) has been developed and can depict a minute vessel in the stalk of a benign polyp without contrast agent administration [43]. On CEUS, adenomas $(0.56 \pm 0.48 \mathrm{~mm})$ demonstrated a significantly wider stalk width compared to cholesterol polyps $(0.23 \pm 0.59 \mathrm{~mm})$, and the stalk width of GBCs was greater than that of benign polyps [44].

\subsection{Localized Slight Thickening of Inner Hypoechoic Layer around GPLs}

The progression of GBCs includes lateral spreading on the mucosal surface (horizontal progress) and deep invasion in the wall (vertical invasion). Lateral spreading is the main route in early-stage GBCs. According to a clinicopathological study on early GBCs, $10 \%$ of pedunculated and $75 \%$ of sessile GBCs were accompanied by laterally spreading components [10]. Eguchi et al. [45] reported that $66 \%$ of early GBCs had superficial spread of carcinoma, and sessile type or superficial raised type was more associated with superficial spreading than pedunculated type. Wakai et al. [46] also reported that $88 \%$ of sessile early-stage GBCs were accompanied by superficially elevated and/or flat tumors. US, especially with a high-frequency transducer with zoom magnification can detect localized slight thickening of the inner hypoechoic layer around GPLs (Figure 9), corresponding to the lateral spreading of flat-type GBCs $[7,47]$.

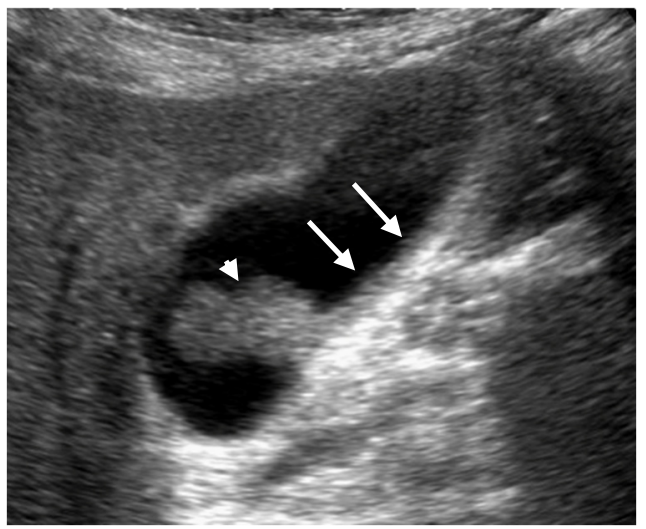

(a)

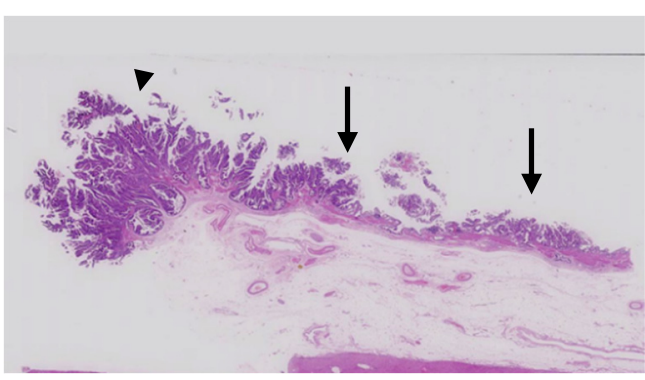

(b)

Figure 9. Localized slight thickening of an inner hypoechoic layer around GPL. (a) HRUS delineated a localized slight thickening of an inner hypoechoic layer (arrow) around a sessile GBC (arrowhead). (b) Histopathologically, this finding corresponded to the laterally spreading of carcinoma (arrow). Reprinted with permission from ref. [7]. Copyright 2021 Japan Society of Ultrasonics in Medicine.

\subsection{Irregularity or Discontinuity of GB Wall Layer Structure}

High-frequency transducers can delineate GB wall as two- or three-layer structure: An innermost hypoechoic layer and an outermost hyperechoic layer or an innermost hyperechoic layer, a middle hypoechoic layer, and an outermost hyperechoic layer. According to a precise comparison of the layer structure of EUS and its histology [48,49], the inner hypoechoic layer includes not only the mucosa and muscularis propria but also the fibrous layer of the subserosa. Therefore, the irregularity of the outer hyperechoic layer of the adjacent wall suggests GBC with invasion into the adipose layer of the subserosa (T2), and the disruption of the outer hyperechoic layer suggests GBC with invasion beyond subserosa [11]. However, sessile GPLs with an intact outer hyperechoic layer include not 
only non-neoplastic GPLs but GBCs confining to the mucosa (T1a) or muscularis propria (T1b), or have invaded the fibrous layer of the subserosa (T2).

In most cases, the characteristics of the GB wall can be evaluated at the boundary between the liver and GB wall using conventional US. CEUS is highly useful for observing the continuity of the GB wall, especially in cases with inflammation or biliary sludge and improve the diagnostic performance. The discontinuity of the GB wall on CEUS showed the high sensitivity and specificity ( $82 \%$ and $93 \%$, respectively) [50]. Xie et al. [51] demonstrated that the disruption of the GB wall on CEUS was the best indicator of malignant lesions with the highest sensitivity and specificity ( $85 \%$ and $100 \%$, respectively).

\subsection{Blood Flow Analysis and Contrast Effect}

Color Doppler imaging is used to detect vessels inside GPLs and GB wall, and evaluate its direction. Since the most recent highly-sensitive Doppler imaging can detect low-flow signals, minute vessels in GPLs can be evaluated without using contrast agents (Figure 10). In previous reports, color signal patterns have been roughly classified into absent, diffuse, dotted, linear, irregular, branched, tortuous, arborizing, and so on. Hirooka et al. [52] reported that color signal patterns of GBCs were diffuse or arborizing (sensitivity $90.5 \%$ and specificity $62.5 \%)$.

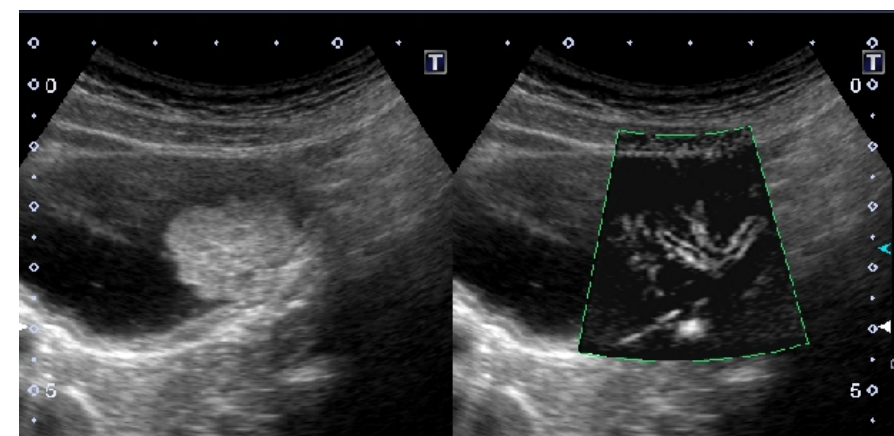

(a)

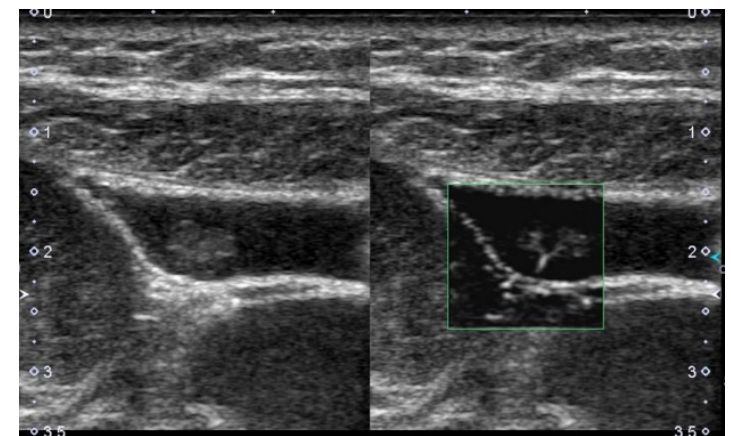

(b)

Figure 10. Vascular imaging using superb microvascular imaging (SMI). (a) Multiple flow signals spreading dendritically from the base into the lesion were delineated in a GBC. (b) A branched signal was detected in a cholesterol polyp.

As for CEUS, Miwa et al. [13] proposed shape (regular or irregular) and thickness (dilated or thin) as parameters for classifying vessels: Vessels of GBC were irregular in $82 \%$ and dilated in $71 \%$, whereas in cases of benign polyps, $95 \%$ had regular and $89 \%$ had thin vessels. Dilated vessels, characterized by caliber changes of approximately $1 \mathrm{~mm}$ in diameter on CEUS, were significantly correlated with malignant GPLs $(p<0.001)$ [13]. Kin et al. [53] reported that contrast-enhanced SMI provided a microvascular image with good quality compared with SMI, and tortuous microvessels and the presence of abrupt caliber change in microvessels showed a significant difference between benign and malignant GB lesions ( $p=0.032, p<0.001$, respectively). However, irregularly shaped signal patterns and dilated blood vessels were detected even in non-neoplastic GPLs in a few cases $[13,52,53]$. Measurement of GB wall blood flow (GWBF) is another clue for differentiation. GBC showed a significantly rapid blood flow value compared with other GB abnormalities and healthy volunteers. When the cut-off level of GWBF velocity was set at $30 \mathrm{~cm} / \mathrm{s}$, GBC could be diagnosed with $100 \%$ sensitivity and $96 \%$ specificity [54].

On CEUS, several reports have evaluated the perfusion effect in the arterial phase (early phase) and venous phase (late phase). However, since GBC, adenoma, inflammatory polyp, and even cholesterol polyp show mild or marked tumor enhancement in the arterial phase, it is considered difficult to differentiate GPLs except biliary sludge using the perfusion effect in the arterial phase. On the other hand, in the venous phase of CEUS, GBC has been reported to show hypoenhancement compared to benign polyps $[50,51,55]$. This "rapid wash-out change" might be related to the abundant blood supply in malignant 
lesions, though there are fewer histological explanations. However, the timing for assessing the degree of enhancement in the venous phase was not the same among previous reports. Therefore, it is controversial to evaluate the usefulness of the "rapid wash-out change" in the differential diagnosis of GPLs.

Heterogeneous enhancement is generally used for the differential diagnosis of liver tumors, and also useful for characterizing GPL [13,55]. Since most hypervascular lesions usually show homogeneous enhancement in the arterial phase, the heterogeneity of enhancement should be evaluated in the venous phase. GBC shows a heterogeneous contrast effect by variate vessel shape and diameter, whereas adenoma and benign polyps show homogeneous enhancement [56].

For the differential diagnosis of GPLs, the classification into pedunculated and sessile is essential. Internal structures such as hyperechoic spots, aggregation of echogenic spots, and cystic structure are highly specific for cholesterol polyps and ADM, respectively. After assessing these findings using a high-resolution transducer, it is recommended to assess the GWBF and shape and caliber change of color signal patterns on Doppler imaging. If CEUS is available, it is also useful to evaluate enhanced pattern in the venous phase (late phase) (Table 1).

Table 1. US findings in major GPLs.

\begin{tabular}{|c|c|c|c|c|}
\hline US Findings & cholesterol Polyp & ADM & Adenoma & Carcinoma \\
\hline US appearance & pedunculated & sessile & $\begin{array}{l}\text { pedunculated }> \\
\text { sessile }\end{array}$ & sessile $>$ pedunculated \\
\hline Multiplicity & multiple > solitary & solitary & solitary & solitary \\
\hline Surface contour & smooth or granular & smooth or granular & nodular or lobulated & nodular or lobulated \\
\hline Internal structure & $\begin{array}{l}\text { hyperechoic spots, } \\
\text { aggregation of } \\
\text { echogenic spots }\end{array}$ & $\begin{array}{l}\text { cystic structures (round } \\
\text { and smooth surface) }\end{array}$ & $\begin{array}{l}\text { cystic structures } \\
\text { (multilobulated and } \\
\text { irregular surface) }\end{array}$ & $\begin{array}{c}\text { cystic structures } \\
\text { (multilobulated and } \\
\text { irregular surface) }\end{array}$ \\
\hline $\begin{array}{l}\text { Localized slight } \\
\text { thickening of inner } \\
\text { hypoechoic layer }\end{array}$ & absent & absent & absent & occasionally \\
\hline GB wall layer structure & $\begin{array}{c}\text { intact outer } \\
\text { hyperechoic layer }\end{array}$ & $\begin{array}{c}\text { intact outer } \\
\text { hyperechoic layer }\end{array}$ & $\begin{array}{c}\text { intact outer } \\
\text { hyperechoic layer }\end{array}$ & $\begin{array}{l}\text { irregular or disrupted } \\
\text { outer hyperechoic layer } \\
\text { in advanced lesions }\end{array}$ \\
\hline $\begin{array}{l}\text { Shape of color } \\
\text { signal pattern }\end{array}$ & absent or regular & absent or regular & irregular & irregular \\
\hline $\begin{array}{c}\text { Caliber change of color } \\
\text { signal pattern }\end{array}$ & absent & absent & present & present \\
\hline $\begin{array}{l}\text { GB wall blood flow } \\
\text { (GWBF) }\end{array}$ & lower than $30 \mathrm{~cm} / \mathrm{s}$ & lower than $30 \mathrm{~cm} / \mathrm{s}$ & not available & higher than $30 \mathrm{~cm} / \mathrm{s}$ \\
\hline $\begin{array}{l}\text { Enhanced pattern in the } \\
\text { venous phase (late phase) }\end{array}$ & homogeneous & homogeneous & homogeneous & heterogeneous \\
\hline
\end{tabular}

\section{Differentiation of GB Wall Thickenings (GWTs)}

The normal GB wall is composed of four layers: Mucosa, muscularis propria, subserosa, and serosa. Under favorable conditions, US, especially when employing highfrequency transducers, can identify two- or three-layers: An innermost hypoechoic layer and an outermost hyperechoic layer or an innermost hyperechoic layer, a middle hypoechoic layer, and an outermost hyperechoic layer. According to the precise comparison of the US layer of the GB wall and histological structure $[48,49]$, the inner hypoechoic layer in a two-layer structure and the hypoechoic middle layer in a three-layer structure include not only the mucosa and muscularis propria but the fibrous layer of the subserosa. The outermost hyperechoic layer represents the serosa and the adipose layer of the subserosal. 
GWTs include wall thickening of $4 \mathrm{~mm}$ or greater and focal presence of a partial inner hypoechoic layer of the GB wall even if the thickness is less than $4 \mathrm{~mm}$ [1] (Figure 3). Kim et al. [57] classified GWT of xanthogranulomatous cholecystitis (XGC) into diffuse $(>50 \%)$ and localized $(<50 \%)$ according to the extent of thickening. Thus, diffuse GWT was defined as a condition in which more than $50 \%$ of the GB wall shows wall thickening of $4 \mathrm{~mm}$ or more (Figure 3c), whereas focal GWT includes not only the wall thickening of $4 \mathrm{~mm}$ or more in less than $50 \%$ of the GB wall (Figure 3d), but also the focal presence of the inner hypoechoic layer, even if the wall thickness is less than $4 \mathrm{~mm}$.

Diffuse GWTs can be seen in the extracholecystic inflammation, hepatic disorders, and systemic diseases, as well as GB disease, and pseudo-thickening is included (Table 2), whereas focal GWTs are specific for GB disorders and the incidence of GBCs is higher. Lee et al. [58] reported that non-focal wall thickening is a statistically common finding for XGC compared to GBC $(p<0.001)$. Cui et al. [59] reported that focal thickening of the GB wall was more frequent in XGC patients concomitant with GBC than those without GBC $(p=0.0117)$.

Table 2. Causes of GB wall thickening (GWT).

\begin{tabular}{|c|c|c|c|}
\hline & & Diffuse GWT & Focal GWT \\
\hline \multirow{6}{*}{ Gallbladder } & \multirow{3}{*}{ Inflammation } & Acute cholecystitis & \multirow{3}{*}{$\begin{array}{l}\text { Chronic cholecystitis } \\
\text { Xanthogranulomatous } \\
\text { cholecystitis }\end{array}$} \\
\hline & & Chronic cholecystitis & \\
\hline & & Xanthogranulomatous cholecystitis & \\
\hline & Hyperplasia & $\begin{array}{l}\text { Adenomyomatosis (Diffuse, Segmental) } \\
\text { Hyperplasia associated with } \\
\text { pancreaticobiliary maljuncton }\end{array}$ & Adenomyomatosis (Focal) \\
\hline & Neoplasia & $\begin{array}{l}\text { Gallbladder carcinoma } \\
\text { Lymphoma }\end{array}$ & Gallbladder carcinoma \\
\hline & Pseudothickening & Postprandial state & Debris, Sludge \\
\hline \multirow{3}{*}{ Other organs } & Inflammation & $\begin{array}{l}\text { Pancreatitis } \\
\text { Peritonitis }\end{array}$ & \\
\hline & Liver disorders & $\begin{array}{l}\text { Acute hepatitis } \\
\text { Cirrhosis }\end{array}$ & \\
\hline & Systemic diseases & $\begin{array}{l}\text { Heart failure } \\
\text { Renal failure } \\
\text { Hypoalbuminemia } \\
\text { Sepsis }\end{array}$ & \\
\hline
\end{tabular}

This classification is highly useful for differential diagnosis. However, since most previous reports have examined GWTs without separating diffuse and focal types, this review also discusses findings of GWTs including both types, except for a few findings.

\subsection{Layer Structure}

5.1.1. Characteristics of Innermost Hyperechoic Layer (IHL)

The source of the innermost hyperechoic layer (IHL) is considered mostly interface echoes [49], and the mucosa is also included [9]. In the acute stage of cholecystitis, thickening of the GB wall is associated with congestion and edema. Therefore, the mucosal surface is well defined and "three-layer" thickening is often present. Thickening of the GB wall unrelated to GB condition, including congestive heart failure, renal failure, liver disease (hepatic failure, hepatitis), ascites, hypoalbuminemia, and pancreatitis, was also due to edema [60]. However, GBCs arise from the GB epithelium and cause mucosal irregularity and disruption in most cases. These differences in the mucosal surface affect the characteristics of IHL. 
The discontinuity of the mucosal echoes, which includes focal or diffuse loss of the normal specular echo from the GB mucosa occurred in $62 \%$ of patients with GBC, compared with only $10 \%$ of patients with benign GB conditions $(p=0.05)$ [61]. According to a comparative study between ADM and early-stage, wall-thickening-type GBC using HRUS, focal IHL discontinuity and IHL irregularity were found in $4.4 \%$ and $11.1 \%$ of patients with ADM and $39.3 \%$ and $85.7 \%$ of patients with GBC and were significantly different $(p<0.001)$ [9]. Furthermore, Lee et al. [58] reported that the continuity of the mucosa was a statistically common finding for XGC compared to GBCs $(p<0.05)$. Multiple logistic regression analysis revealed that the inner layer discontinuity on CEUS was an independent predictor of malignant GWT and achieved the highest diagnostic performance in ROC analysis [62].

Pancreaticobiliary maljunction (PBM) is a congenital anomaly defined as a junction of the pancreatic and bile ducts located outside the duodenal wall and a risk factor for GBC development via the hyperplasia-dysplasia-carcinoma sequence. The incidence of mucosal hyperplasia of PBM patients without biliary dilatation was reported to be $72 \%$ [63] to $91 \%$ [64]. The GB wall appeared as thickening of the inner hypoechoic layer without IHL and outermost hyperechoic layer (Figure 11). Histologically, the GB of PBM without biliary dilatation showed wall thickness composed of epithelial hyperplasia $(88 \%)$, hypertrophic muscular layer (63\%), and subserosal fibrosis (88\%) [65].

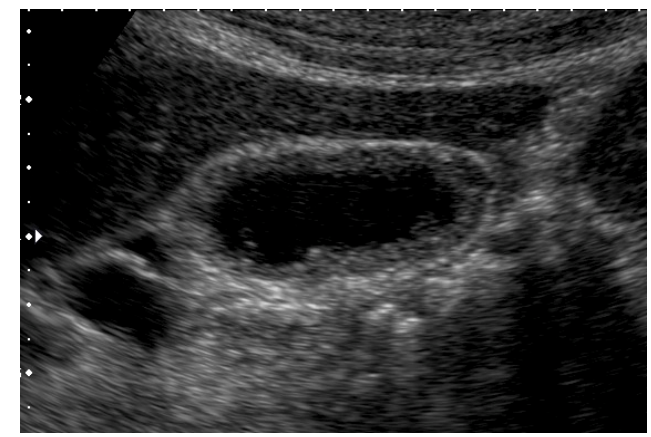

(a)

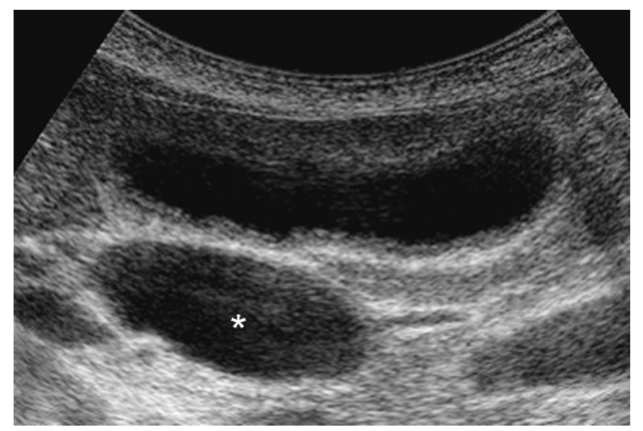

(b)

Figure 11. Diffuse GWT without IHL in pancreaticobiliary maljunction (PBM). US showed thickening of the inner hypoechoic layer without the presence of IHL and outermost hyperechoic layer. (a) PBM without biliary dilatation, (b) PBM concomitant with biliary dilatation (*: dilated extrahepatic bile duct).

The thickening of IHL is also useful for differentiation. When low papillary tumors aggregate on the mucosal surface, distortion of mucosal structures and echo scattering may occur, indicating thickening of IHL (Figure 12). According to a study using HRUS, IHL thickening greater than $1 \mathrm{~mm}$ was significantly associated with GBCs $(p<0.05)$ [9].

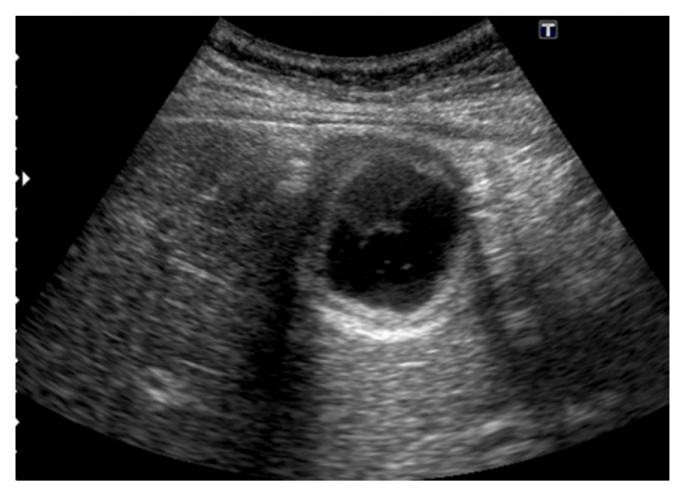

Figure 12. Thickening of IHL. US showed thickened IHL and irregular layer structures of diffuse GWT (GBC case). 


\subsubsection{Sonolucent Layer, Hypoechoic Zone, “Three-Layer" Thickening}

Wall thickening in acute cholecystitis presents relatively uniform thickness of layer structure, showing as a sonolucent layer between two echogenic lines in the GB wall. A hyporeflective or sonolucent layer within the thickened GB wall probably reflects the subserosal edema and necrosis [66]. Submucosal echolucency was significantly more common in patients with benign GB disease than in patients with GBC $(p=0.01)$ [61]. However, a wall sonolucency was seen in only $39 \%$ of acute cholecystitis and $4 \%$ in chronic cases [67]. A "three-layer" thickening, which consists of a single circumferential lucent zone between two relatively uniform echogenic layers is also used as the same finding. Cohan et al. [68] reported that the sensitivity and specificity of a "three-layer" thickening for acute cholecystitis were only $8 \%$ and $71 \%$, respectively.

\subsubsection{Striations}

Striations are striated wall thickening, consisting of several alternating, irregular, discontinuous, lucent, and echogenic bands, and observed diffusely or focally in the GB wall. Striations, which are due to edema of the GB wall, have been considered strong evidence for acute cholecystitis, showing the sensitivity of only $62 \%$, but the specificity of $100 \%$ [68]. Unlike uncomplicated acute cholecystitis, in which inflammation is limited primarily to the submucosal layer of the GB wall, coagulative necrosis often involves all layers of the GB wall in XGC. Therefore, the presence of striations in acute cholecystitis was suggestive of gangrenous changes in the GB wall [60].

However, striations may occur in various diseases, including congestive heart failure, renal failure, liver disease (hepatic failure, hepatitis), ascites, hypoalbuminemia, and pancreatitis [60,69]. Hepatitis A virus infection (odds ratio $=3.17$ [1.42-7.09]), female gender (odds ratio $=2.47$ [1.34-4.56]), and an elevated total bilirubin level (odds ratio $=1.09$ [1.03-1.15]) were positively associated with GWT secondary to hepatitis [69]. The enlarged GB cavity is characteristic of cholecystitis and is useful in differentiating striations due to other causes.

5.1.4. Irregularity or Discontinuity of Layer Structure, Irregular Thickening of Outer Hyperechoic Layer

The wall thickening due to edema, including acute cholecystitis and systemic diseases, shows a relatively uniform thickness and appears as a "three-layer" layer structure: An innermost hyperechoic layer, a middle hypoechoic layer, and an outermost hyperechoic layer. However, XGC is difficult to differentiate from GBC because the interface with the liver is often lost due to the characteristic pathological pattern of lipid-containing histiocytes infiltrating

Typical US findings in wall thickening GBC include hypoechoic, irregular wall thickening due to tumor invasion. According to a study using HRUS, loss of the multiple layer pattern was detected in $64.3 \%$ of wall-thickening-type GBC [9]. Furthermore, tumor invasion into the adipose layer of the subserosa causes the irregularity of the outer hyperechoic layer and tumor invasion beyond the subserosa causes the discontinuity of the outer hyperechoic layer [49] (Figure 13). On CEUS, the destruction of the GB wall intactness was absent in benign diseases, and the sensitivity, specificity, and accuracy in the differential diagnosis between malignant and benign GB diseases were $84.8 \%, 100 \%$, and $93.8 \%$, respectively [51]. According to a systematic review of CEUS, discontinuity of the GB wall in differentiating benign and malignant diseases showed the highest sensitivity $(82 \%)$ and specificity (93\%) among all malignant features on CEUS [50].

An irregularly thickened outer hyperechoic layer is also useful for differential diagnosis. Joe et al. [9] reported that the sensitivity and specificity of irregular thickness of an outer hyperechoic wall for the diagnosis of ADM or wall-thickening-type GBC were 57.1\% and $88.9 \%$, respectively. 


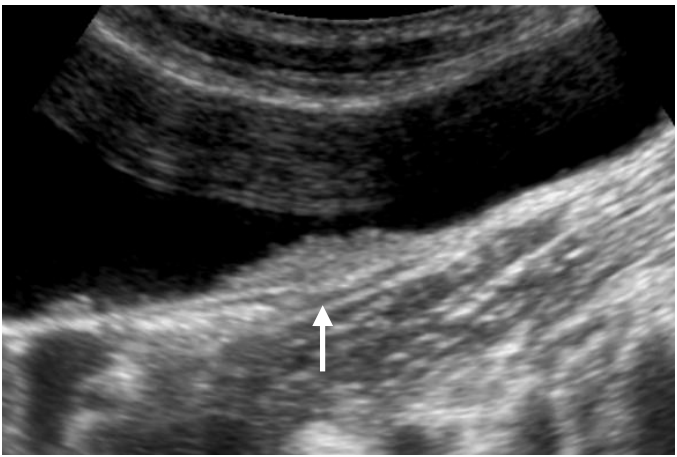

(a)

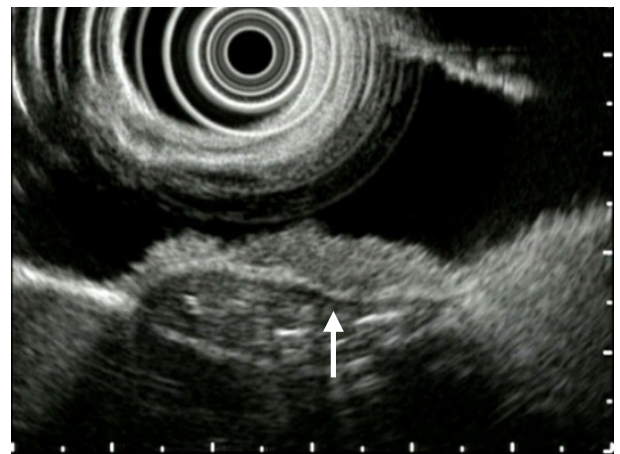

(b)

Figure 13. Discontinuity of an outer hyperechoic layer. A high-frequency transducer showed the discontinuity of an outer hyperechoic layer (arrow) in focal GWT (a), EUS also delineated the thinning of an outer hyperechoic layer (arrow) (b) (GBC case).

\subsection{Internal Structure}

5.2.1. Cystic Structures (Anechoic Spots), Comet-Tail Artifacts, Echogenic Foci

Cystic structures (anechoic spots) and comet-tail artifacts reflect RAS and characteristic findings of ADM. However, conventional US had an accuracy of only $66 \%$ for the diagnosis of ADM [34]. However, HRUS has been reported to delineate cystic lesions with a sensitivity of $51.1 \%$ even in small cystic lesions of less than $3 \mathrm{~mm}$ in diameter [9]. The sensitivity, specificity, and accuracy of intramural cystic spaces/echogenic foci for the diagnosis of ADM using HRUS were $80.0 \%, 85.7 \%$, and $82.2 \%$, respectively [9]. On CEUS, small anechoic spaces observed in both arterial and venous phases were characteristic finding of ADM. Tang et al. [35] demonstrated that the sensitivity of CEUS (100\%) in the detection of RAS in focal type of ADM was significantly higher than conventional US (66.7\%).

Segmental ADM is a high-risk condition for GBC [41,70,71] (Figure 14), especially in patients older than 60 years old $[70,71]$. Since epithelial metaplasia was more marked in the fundal mucosa of segmental ADM than in the neck mucosa $(p=0.003)$ [70], GBC arose in the mucosa of the fundal compartment distal to the annular stricture of the segmental type ADM [71].

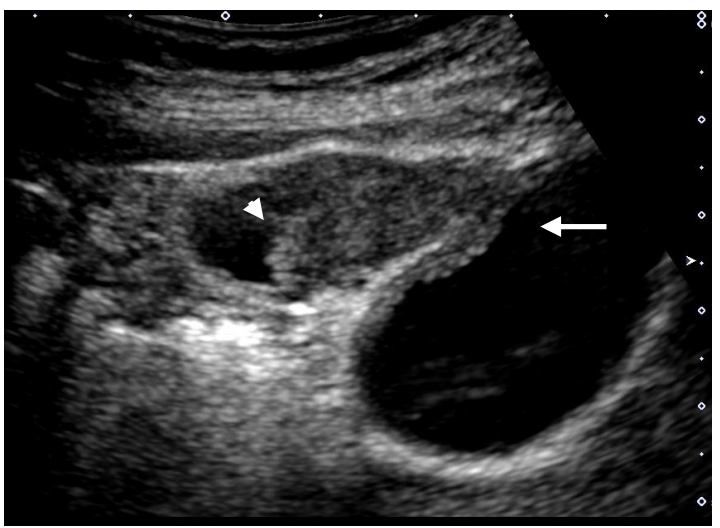

Figure 14. GBC concomitant with segmental ADM. A high-frequency transducer delineated a hypoechoic sessile GBC (arrowhead) in the fundus distal to the annular stricture (arrow).

\subsubsection{Hypoechoic Nodules and Bands}

XGC is characterized by distinct pathological findings such as fat-laden macrophages and foamy histiocytes and is associated with severe fibrosis. Several reports $[57,58,72]$ suggested that hypoechoic nodules and bands in the GB wall were the most characteristic findings in XGC. Intramural nodules were discrete, oval or flat, with low echogenicity, and ranged in size from 6 to $12 \mathrm{~mm}$ (mean, $10.5 \mathrm{~mm}$ ) [57]. Lee et al. [58] reported that 
intramural nodules were found in $70.8 \%$ of XGC and $31.6 \%$ of GBCs on HRUS, and a statistically more common finding in XGC $(p=0.015)$. A comparative study between US images and pathological findings of the resected specimen showed well-defined hypoechoic areas corresponding to the xanthogranulomatous foci [72]. These lesions were thought to be due to the rupture of the RAS with intramural extravasation of bile and subsequent xanthogranulomatous [73].

\subsection{Shape of the GB (Symmetrical or Asymmetrical)}

In diffuse GWT, diffuse-type ADM involves the whole GB wall symmetrically and segmental ADM narrows the lumen symmetrically. XGC can cause asymmetrical thickening of the GB wall and demonstrate a tendency to form nodules. In focal GWT, most benign lesions were symmetrical $(68.8 \%)$, while asymmetrical thickening was more common in GBCs $(75 \%, p<0.05)[74]$.

\subsection{Cholecystolithiasis}

Gallstones are common in acute or chronic cholecystitis and XGC, and are relatively common in GBC and ADM. Ninety-five percent of acute cholecystitis is due to an obstructing calculus in the neck of the GB or cystic duct, while stones are usually absent in diffuse GWTs secondary to acute hepatitis, liver cirrhosis, heart failure, renal failure, and hypoalbuminemia.

Wibbenmeyer et al. [61] reported that cholelithiasis was present in $85 \%$ of unsuspected GBCs, and a large solitary gallstone $(p=0.005)$ and a displaced stone $(p=0.01)$ were statistically significantly more common in patients with unsuspected GBC. According to the study of cholecystectomy cases, the prevalence of cholecystolithiasis was higher in patients with segmental ADM $(88.9 \%)$ than in those without ADM $(52.3 \% ; p<0.001)$, especially in cases with hourglass deformity [75]. Lee et al. [58] compared the diagnostic performance of HRUS, CT, and MRI in differentiating between XGC and GBC, and reported that coexistence of gallstones $(\mathrm{OR}=16.5)$ was independently associated with XGC $(p=0.013)$.

\subsection{Blood Flow Analysis}

Color Doppler is useful in the evaluation of inflammatory disorders including vasodilatation and increased flow. Patients with acute cholecystitis had an abnormally increased flow in the distal two-thirds of the thickened GB wall; however, patients with chronic cholecystitis and necrotizing cholecystitis did not show increased flow [76]. Joo et al. [9] reported that intralesional vascularity on color Doppler imaging was significantly associated with wall-thickening-type GBC and was a negative predictor of ADM $(p<0.001)$.

GWBF velocity in acute cholecystitis $(28.6 \pm 7.1 \mathrm{~cm} / \mathrm{s})$ showed a tendency to be faster than chronic cholecystitis $(20.8 \pm 4.6 \mathrm{~cm} / \mathrm{s})$ and ADM $(16.8 \pm 4.8 \mathrm{~cm} / \mathrm{s})$ [54] (Figure 15). GBC $(49.4 \pm 12.6 \mathrm{~cm} / \mathrm{s})$ showed significantly higher GWBF velocity $(p<0.01)$, and the sensitivity and specificity with the cut-off level at $30 \mathrm{~cm} / \mathrm{s}$ were $100 \%$ and $96 \%$, respectively [54]. Kawashima et al. [77] reported that the mean GWBF velocity of PBM $(29.4 \pm 3.9 \mathrm{~cm} / \mathrm{s})$ was significantly higher $(p<0.0001 ; 95 \%$ CI 5.48-13.2) than those without PBM $(20.1 \pm 5.9 \mathrm{~cm} / \mathrm{s})$, and the cut-off level appropriate for diagnosing PBM was estimated to be $25 \mathrm{~cm} / \mathrm{s}$. They also speculated that cell proliferation enhancing in the GB wall may contribute to a higher GWBF velocity in cases without GBC.

For the differential diagnosis of GWT, the classification into diffuse and focal is essential. For diffuse GWT, evaluation of other organs in addition to the gallbladder is necessary. The discontinuity and irregularity of the innermost hyperechoic layer and irregular or disrupted GB wall layer structure using a high-resolution transducer suggest GBC. Rapid GWBF is useful not only for the diagnosis of wall-thickened type GBC, but the detection of pancreaticobiliary maljunction (Table 3). 


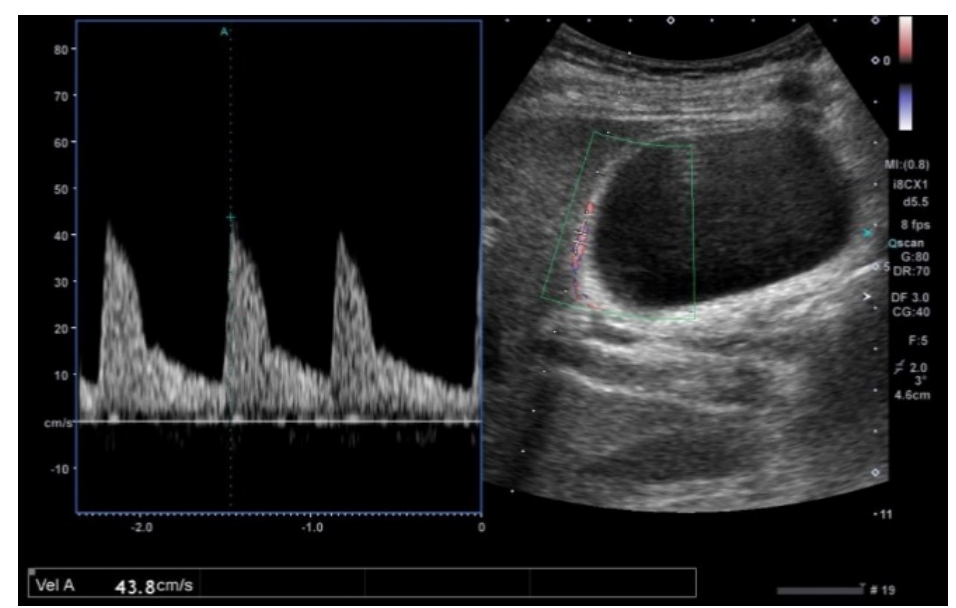

Figure 15. GWBF velocity. GWBF velocity showed $43.8 \mathrm{~cm} / \mathrm{s}$ in acute cholecystitis.

Table 3. US findings in major GWT.

\begin{tabular}{|c|c|c|c|c|}
\hline US Findings & Acute Cholecystitis & XGC & ADM & Carcinoma \\
\hline US appearance & diffuse & focal or diffuse & focal or diffuse & focal $>$ diffuse \\
\hline $\begin{array}{l}\text { Innermost Hyperechoic } \\
\text { Layer (IHL) }\end{array}$ & $\begin{array}{l}\text { recognized } \\
\text { continuously }\end{array}$ & $\begin{array}{l}\text { recognized } \\
\text { continuously }\end{array}$ & $\begin{array}{l}\text { recognized } \\
\text { continuously }\end{array}$ & $\begin{array}{l}\text { presence of focal or } \\
\text { diffuse discontinuity or } \\
\text { irregularity }\end{array}$ \\
\hline Layer structure & $\begin{array}{c}\text { preserved, sonolucent } \\
\text { layer, striations }\end{array}$ & $\begin{array}{l}\text { irregular or disrupted } \\
\text { in some cases }\end{array}$ & preserved & $\begin{array}{l}\text { irregular or disrupted } \\
\text { in advanced lesions }\end{array}$ \\
\hline Internal structure & No distinctive findings & $\begin{array}{l}\text { hypoechoic nodules } \\
\text { and bands }\end{array}$ & $\begin{array}{l}\text { cystic structures (round } \\
\text { and smooth surface, } \\
\text { aligned in a linear } \\
\text { fashion) }\end{array}$ & $\begin{array}{l}\text { cystic structures } \\
\text { (multilobulated and } \\
\text { irregular surface) }\end{array}$ \\
\hline Cholecystolithiasis & common & common & relatively common & relatively common \\
\hline $\begin{array}{l}\text { GB wall blood flow } \\
\text { (GWBF) }\end{array}$ & $\begin{array}{c}\text { lower than } 30 \mathrm{~cm} / \mathrm{s} \\
\text { (affected by } \\
\text { disease activity) }\end{array}$ & not available & lower than $30 \mathrm{~cm} / \mathrm{s}$ & higher than $30 \mathrm{~cm} / \mathrm{s}$ \\
\hline
\end{tabular}

\section{Conclusions}

For the differential diagnosis of GB lesions, morphological classification of US appearance is essential. The diagnostic performance of US can be further improved by combining detailed B-mode evaluation using high-frequency transducers with highly sensitive Doppler imaging and CEUS.

Funding: This research received no external funding.

Institutional Review Board Statement: All procedures followed were in accordance with the ethical standards of the Responsible Committee on Human Experimentation (institutional and national) and with the Helsinki Declaration of 1964 and later versions.

Informed Consent Statement: Informed consent was obtained from all patients for being included in the study.

Conflicts of Interest: The author declares no conflict of interest. 


$\begin{array}{ll}\text { Abbreviations } \\ \text { ADM } & \text { adenomyomatosis } \\ \text { CEUS } & \begin{array}{l}\text { contrast-enhanced ultrasound } \\ \text { endoscopic ultrasound }\end{array} \\ \text { EUS } & \text { gallbladder } \\ \text { GB } & \text { gallbladder carcinoma } \\ \text { GBC } & \text { gallbladder polypoid lesion } \\ \text { GPL } & \text { gallbladder wall blood flow } \\ \text { GWBF } & \text { gallbladder wall thickening } \\ \text { GWT } & \text { high-resolution ultrasound } \\ \text { HRUS } & \text { innermost hyperechoic layer } \\ \text { IHL } & \text { pancreaticobiliary maljunction } \\ \text { PBM } & \text { Rokitansky-Aschoff sinuses } \\ \text { RAS } & \text { superb microvascular imaging } \\ \text { SMI } & \text { ultrasound } \\ \text { US } & \text { xanthogranulomatous cholecystitis } \\ \text { XGC } & \end{array}$

\section{References}

1. Manual for Abdominal Ultrasound in Cancer Screening and Health Checkups. Available online: https://www.ningen-dock.jp/ wp/wp-content/uploads/2018/06/Abdominal-Ultrasound.pdf (accessed on 22 March 2021).

2. Mihara, S.; Nagano, K.; Kuroda, K.; Yoshioka, R.; Sawatari, M.; Koba, H.; Tanaka, S.; Hirao, S.; Machihara, M.; Hondou, K.; et al. Efficacy of Ultrasonic Mass Survey for Abdominal Cancer. J. Med. Syst. 1998, 22, 55-62. [CrossRef]

3. Elmasry, M.; Lindop, D.; Dunne, D.F.; Malik, H.; Poston, G.J.; Fenwick, S.W. The risk of malignancy in ultrasound detected gallbladder polyps: A systematic review. Int. J. Surg. 2016, 33 Pt A, 28-35. [CrossRef]

4. De Groen, P.C.; Gores, G.J.; LaRusso, N.F.; Gunderson, L.L.; Nagorney, D.M. Biliary tract cancers. N. Engl. J. Med. 1999, 341, 1368-1378. [CrossRef]

5. Miyazaki, M.; Yoshitomi, H.; Miyakawa, S.; Uesaka, K.; Unno, M.; Endo, I.; Ota, T.; Ohtsuka, M.; Kinoshita, H.; Shimada, K.; et al. Clinical practice guidelines for the management of biliary tract cancers 2015: The 2nd English edition. J. Hepatobiliary Pancreat. Sci. 2015, 22, 249-273. [CrossRef] [PubMed]

6. Kiriyama, S.; Kozaka, K.; Takada, T.; Strasberg, S.M.; Pitt, H.A.; Gabata, T.; Hata, J.; Liau, K.-H.; Miura, F.; Horiguchi, A.; et al. Tokyo Guidelines 2018: Diagnostic criteria and severity grading of acute cholangitis (with videos). J. Hepatobiliary Pancreat. Sci. 2018, 25, 17-30. [CrossRef] [PubMed]

7. Okaniwa, S. Role of conventional ultrasonography in the diagnosis of gallbladder polypoid lesions. J. Med. Ultrason. 2019. [CrossRef] [PubMed]

8. $\quad$ Kim, J.H.; Lee, J.Y.; Baek, J.H.; Eun, H.W.; Kim, Y.J.; Han, J.K.; Choi, B.I. High-resolution sonography for distinguishing neoplastic gallbladder polyps and staging gallbladder cancer. Am. J. Roentgenol. 2015, 204, W150-W159. [CrossRef]

9. Joo, I.; Lee, J.Y.; Kim, J.H.; Kim, S.J.; Kim, M.A.; Han, J.K.; Choi, B.I. Differentiation of adenomyomatosis of the gallbladder from early-stage, wall-thickening-type gallbladder cancer using high-resolution ultrasound. Eur. Radiol. 2013, 23, 730-738. [CrossRef] [PubMed]

10. Okaniwa, S.; Fujita, N.; Noda, Y.; Kobayashi, G.; Kimura, K.; Yago, A.; Mochizuki, F.; Yamazaki, T.; Sawai, T. A clinico-pathological study of early gallbladder carcinoma. Jpn. J. Gastroenterol. 1996, 93, 628-633, (In Japanese with English abstract).

11. Fujita, N.; Noda, Y.; Kobayashi, G.; Kimura, K.; Yago, A. Diagnosis of the depth of invasion of gallbladder carcinoma by EUS. Gastrointest. Endosc. 1999, 50, 659-663. [CrossRef]

12. Iri, M.; Takehara, Y.; Matsuzawa, K.; Yasui, H.; Oka, T. Gallbladder carcinoma with ultrasonographically intact outer hypoechoic layer: A sign of a favorable outcome. J. Med. Ultrason. 2002, 29, 105-112. [CrossRef]

13. Miwa, H.; Numata, K.; Sugimori, K.; Sanga, K.; Hirotani, A.; Tezuka, S.; Goda, Y.; Irie, K.; Ishii, T.; Kaneko, T.; et al. Differential diagnosis of gallbladder polypoid lesions using contrast-enhanced ultrasound. Abdom. Radiol. 2019, 44, 1367-1378. [CrossRef] [PubMed]

14. Ishikawa, T.; Kawashima, H.; Ohno, E.; Iida, T.; Nishio, R.; Suzuki, H.; Uetsuki, K.; Yashika, J.; Yamada, K.; Yoshikawa, M.; et al. Usefulness of transabdominal three-dimensional ultrasound for the evaluation of elevated gallbladder lesions. Tando 2020, 34, 145-152, (In Japanese with English abstract).

15. Kubota, K.; Bandai, Y.; Noie, T.; Ishizaki, Y.; Teruya, M.; Makuuchi, M. How should polypoid lesions of the gallbladder be treated in the era of laparoscopic cholecystectomy? Surgery 1995, 117, 481-487. [CrossRef]

16. Sun, X.J.; Shi, J.S.; Han, Y.; Wang, J.S.; Ren, H. Diagnosis and treatment of polypoid lesions of the gallbladder: Report of 194 cases. Hepatobiliary Pancreat. Dis. Int. 2004, 3, 591-594.

17. Bhatt, N.R.; Gillis, A.; Smoothey, C.O.; Awan, F.N.; Ridgway, P.F. Evidence based management of polyps of the gallbladder: A systematic review of the risk factors of malignancy. Surgeon 2016, 14, 278-286. [CrossRef] 
18. Choi, T.W.; Kim, J.H.; Park, S.J.; Ahn, S.J.; Joo, I.; Han, J.K. Risk stratification of gallbladder polyps larger than $10 \mathrm{~mm}$ using high-resolution ultrasonography and texture analysis. Eur. Radiol. 2018, 28, 196-205. [CrossRef]

19. Wiles, R.; Varadpande, M.; Muly, S.; Webb, J. Growth rate and malignant potential of small gallbladder polyps-Systematic review of evidence. Surgeon 2014, 12, 221-226. [CrossRef]

20. Kozuka, S.; Tsubone, N.; Yasui, A.; Hachisuka, K. Relation of adenoma to carcinoma in the gallbladder. Cancer 1982, 50, $2226-2234$. [CrossRef]

21. Park, H.Y.; Oh, S.H.; Lee, K.H.; Lee, J.K.; LeeIs, K.T. Cholecystectomy a reasonable treatment option for simple gallbladder polyps larger than $10 \mathrm{~mm}$ ? World J. Gastroenterol. 2015, 21, 4248-4254. [CrossRef]

22. Taskin, O.C.; Basturk, O.; Reid, M.D.; Dursun, N.; Bagci, P.; Saka, B.; Balci, S.; Memis, B.; Bellolio, E.; Araya, J.C.; et al. Gallbladder polyps: Correlation of size and clinicopathologic characteristics based on updated definitions. PLoS ONE 2020, 15, e0237979. [CrossRef]

23. Kimura, K. Diagnosis for pedunculated polypoid lesions of the gallbladder by endoscopic ultrasonography. Jpn. J. Gastroenterol. 1997, 94, 249-260, (In Japanese with English abstract).

24. Choi, W.B.; Lee, S.K.; Kim, M.H.; Seo, D.W.; Kim, H.J.; Kim, D.I.; Park, E.T.; Yoo, K.S.; Lim, B.C.; Myung, S.J.; et al. A new strategy to predict the neoplastic polyps of the gallbladder based on a scoring system using EUS. Gastrointest. Endosc. 2000, 52, 372-379. [CrossRef] [PubMed]

25. Sugiyama, M.; Atomi, Y.; Kuroda, A.; Muto, T.; Wada, N. Large cholesterol polyps of the gallbladder: Diagnosis by means of US and endoscopic US. Radiology 1995, 196, 493-497. [CrossRef] [PubMed]

26. Sugiyama, M.; Xie, X.Y.; Atomi, Y.; Saito, M. Differential diagnosis of small polypoid lesions of the gallbladder: The value of endoscopic ultrasonography. Ann. Surg. 1999, 229, 498-504. [CrossRef]

27. Sadamoto, Y.; Oda, S.; Tanaka, M.; Hanada, N.; Kubo, H.; Eguchi, T.; Nawata, H. A useful approach to the differential diagnosis of small polypoid lesions of the gallbladder, utilizing an endoscopic ultrasound scoring system. Endoscopy 2002, 34, 959-965. [CrossRef] [PubMed]

28. Akiyama, T.; Sahara, H.; Seto, K.; Saito, H.; Kiriyama, M.; Tomita, F.; Kosaka, T.; Kita, I.; Takashima, S.; Matsunou, H. Gallbladder cancer associated with cholesterosis. J. Gastroenterol. 1996, 31, 470-474. [CrossRef]

29. Niizawa, M.; Itoh, M.; Mukohjima, T.; Ishida, H.; Ishioka, T.; Nakmaura, J.; Naganuma, T.; Morikawa, P.; Masamune, O. Ultrasonographic features of papillary adenoma of the gallbladder. Jpn. J. Med. Ultrason. 1991, 18, 168-173, (In Japanese with English abstract).

30. Noda, Y.; Kobayashi, G.; Ito, K.; Horaguchi, J.; Iwashita, Y.; Koshida, S.; Kanno, Y.; Ogawa, T.; Masu, K.; Michikawa, Y.; et al. Pyloric-type adenoma and carcinoma in adenoma of the gallbladder, their imaging and histological findings. Tando 2015, 29, 74-84, (In Japanese with English abstract).

31. Yoshimitsu, K.; Irie, K.; Aibe, H.; Tajima, T.; Nishie, A.; Asayama, Y.; Matake, K.; Yamaguchi, K.; Matsuura, S.; Honda, H. Well-differentiated adenocarcinoma of the gallbladder with intratumoral cystic components due to abundant mucin production: A mimicker of adenomyomatosis. Eur. Radiol. 2005, 15, 229-233. [CrossRef]

32. Lichtenstein, J.E. Adenomyomatosis and cholesterosis: The "hyperplastic cholecystosis". In Radiology of the Liver, Biliary Tract, and Pancreas, 1st ed.; Friedman, A.C., Dachman, A.H., Eds.; Mosby: St. Louis, MO, USA, 1994; pp. 539-553.

33. Raghavendra, B.N.; Subramanyam, B.R.; Balthazar, E.J.; Horii, S.C.; Megibow, A.J.; Hilton, S. Sonography of adenomyomatosis of the gallbladder: Radiologic-pathologic correlation. Radiology 1983, 146, 747-752. [CrossRef]

34. Yoshimitsu, K.; Honda, H.; Aibe, H.; Shinozaki, K.; Kuroiwa, T.; Irie, H.; Asayama, Y.; Masuda, K. Radiologic diagnosis of adenomyomatosis of the gallbladder: Comparative study among MRI, helical CT, and transabdominal US. J. Comput. Assist. Tomogr. 2001, 25, 843-850. [CrossRef]

35. Tang, S.S.; Huang, L.P.; Wang, Y.; Wang, Y.J. Contrast-enhanced ultrasonography diagnosis of fundal localized type of gallbladder adenomyomatosis. BMC Gastroenterol. 2015, 15, 99. [CrossRef]

36. Yuan, H.X.; Wang, W.P.; Guan, P.S.; Lin, L.W.; Wen, J.X.; Yu, Q.; Chen, X.J. Contrast-enhanced ultrasonography in differential diagnosis of focal gallbladder adenomyomatosis and gallbladder cancer. Clin. Hemorheol. Microcirc. 2018, 70, 201-211. [CrossRef] [PubMed]

37. Kawarada, Y.; Sanda, M.; Mizumoto, R.; Yatani, R. Early carcinoma of the gallbladder, noninvasive carcinoma originating in the Rokitansky-Aschoff sinus: A case report. Am. J. Gastroenterol. 1986, 81, 61-66. [PubMed]

38. Kurihara, K.; Mizuseki, K.; Ninomiya, T.; Shoji, I.; Kajiwara, S. Carcinoma of the gallbladder arising in adenomyomatosis. Acta Pathol. Jpn. 1993, 43, 82-85. [PubMed]

39. Katoh, T.; Nakai, T.; Hayashi, S.; Satake, T. Noninvasive carcinoma of the gallbladder arising in localized type adenomyomatosis. Am. J. Gastroenterol. 1998, 83, 670-674.

40. Patel, S.; Slade, J.; Jakate, S. An Unusual Case of Noninvasive Adenocarcinoma Arising in a Localized Adenomyoma of the Gallbladder and Review of Literature. Int. J. Surg. Pathol. 2016, 24, 341-346. [CrossRef]

41. Kin, T.; Maguchi, H.; Takahashi, K.; Katanuma, A.; Osanai, M.; Yane, K.; Takagi, R.; Matsumoto, K.; Matsumori, T.; Gon, K.; et al. Clinicopathological features of gallbladder cancer with adenomyomatosis. Tando 2014, 28, 633-640, (In Japanese with English abstract).

42. Kurtz, A.B.; Middleton, W.D. Ultrasound; Mosby: St. Louis, MO, USA, 1996. 
43. Miwa, H.; Numata, K.; Sugimori, K.; Kaneko, T.; Maeda, S. Vascular evaluation using transabdominal ultrasound for gallbladder polyps. J. Med. Ultrason. 2020. [CrossRef]

44. Fei, X.; Lu, W.P.; Luo, Y.K.; Xu, J.H.; Li, Y.M.; Shi, H.Y.; Jiao, Z.Y.; Li, H. Contrast-enhanced ultrasound may distinguish gallbladder adenoma from cholesterol polyps: A prospective case-control study. Abdom. Imaging 2015, 40, 2355-2363. [CrossRef] [PubMed]

45. Eguchi, H.; Ishikawa, O.; Ohigashi, H.; Kasugai, T.; Yokoyama, S.; Yamada, T.; Doki, Y.; Murata, K.; Miyashiro, I.; Sasaki, Y.; et al Surgical Significance of Superficial Cancer Spread in Early Gallbladder Cancer. Jpn. J. Clin. Oncol. 2005, 35, 134-138. [CrossRef] [PubMed]

46. Wakai, T.; Ajioka, Y.; Nagino, N.; Yamaguchi, N.; Shirai, Y.; Hatakeyama, K. Morphological features of early gallbladder carcinoma. Hepatogastroenterology 2012, 59, 1013-1017. [CrossRef] [PubMed]

47. Kimura, K.; Fujita, N.; Noda, Y.; Kobayashi, G.; Itoh, K.; Horaguchi, J.; Takasawa, O. A case of pedunculated polypoid cancer associated with flat-type cancer of the gallbladder. Dig. Endosc. 2005, 17, 93-96. [CrossRef]

48. Aibe, T.; Noguchi, T.; Ohtani, T.; Fuji, T.; Takemoto, T. A study on layers structure of the gallbladder by endoscopic ultrasonography-including normal cases and chronic cholecystitis. JSUM Proc. 1986, 48, 761-762, (In Japanese with English abstract).

49. Fujita, N.; Noda, Y.; Kobayashi, G.; Kimura, K.; Yago, A.; Mochizuki, F. Analysis of the layer structure of the gallbladder by endoscopic ultrasound using the pinning method. Dig. Endosc. 1995, 4, 353-356. [CrossRef]

50. Cheng, Y.; Wang, M.; Ma, B.; Ma, X. Potential role of contrast enhanced ultrasound for the differentiation of malignant and benign gallbladder lesions in East Asia: A meta-analysis and systematic review. Medicine 2018, 97, e11808. [CrossRef]

51. Xie, X.H.; Xu, H.X.; Xie, X.Y.; Lu, M.D.; Kuang, N.; Xu, Z.F.; Liu, G.J.; Wang, Z.; Liang, J.Y.; Chen, L.D.; et al. Differential diagnosis between benign and malignant gallbladder diseases with real-time contrast-enhanced ultrasound. Eur. Radiol. 2010, 20, 239-248. [CrossRef]

52. Hirooka, Y.; Naitoh, Y.; Goto, H.; Furukawa, T.; Ito, A.; Hayakawa, T. Differential diagnosis of gall-bladder masses using color Doppler ultrasonography. J. Gastroenterol. Hepatol. 1996, 11, 840-846. [CrossRef]

53. Kin, T.; Nagai, K.; Hayashi, T.; Takahashi, K.; Katanuma, A. Efficacy of superb microvascular imaging of ultrasound for diagnosis of gallbladder lesion. J. Hepatobiliary Pancreat. Sci. 2020, 27, 977-983. [CrossRef] [PubMed]

54. Hayakawa, S.; Goto, H.; Hirooka, Y.; Itoh, A.; Taki, T.; Watanabe, Y.; Hayakawa, T.; Naitoh, Y. Color Doppler-guided spectral analysis of gallbladder wall flow. J. Gastroenterol. Hepatol. 1998, 13, 181-185. [CrossRef]

55. Sun, L.P.; Guo, L.H.; Hu, H.X.; Liu, L.N.; Xu, J.M.; Zhang, Y.F.; Liu, C.; Bo, X.W.; Xu, X.H. Value of contrast-enhanced ultrasound in the differential diagnosis between gallbladder adenoma and gallbladder adenoma canceration. Int. J. Clin. Exp. Med. 2015, 8 , 1115-1121.

56. Zhang, H.P.; Bai, M.; Gu, J.Y.; He, Y.Q.; Qiao, X.H.; Du, L.F. Value of contrast-enhanced ultrasound in the differential diagnosis of gallbladder lesion. World J. Gastroenterol. 2018, 24, 744-751. [CrossRef]

57. Kim, P.N.; Ha, H.K.; Kim, Y.H.; Lee, M.G.; Kim, M.H.; Auh, Y.H. US findings of Xanthogranulomatous cholecystitis. Clin. Radiol. 1998, 53, 290-292. [CrossRef]

58. Lee, E.S.; Kim, J.H.; Joo, I.; Lee, J.Y.; Han, J.K.; Choi, B.I. Xanthogranulomatous cholecystitis: Diagnostic performance of US, CT, and MRI for differentiation from gallbladder carcinoma. Abdom. Imaging 2015, 40, 2281-2292. [CrossRef] [PubMed]

59. Cui, Y.; Zhang, H.; Zhao, E.; Cui, N.; Li, Z. Differential Diagnosis and Treatment Options for Xanthogranulomatous Cholecystitis. Med. Princ. Pr. 2013, 22, 18-23. [CrossRef] [PubMed]

60. Teefey, S.A.; Baron, R.L.; Bigler, S.A. Sonography of the Gallbladder: Significance of Striated (Layered) Thickening of the Gallbladder Wall. Am. J. Roentgenol. 1991, 156, 945-947. [CrossRef] [PubMed]

61. Wibbenmeyer, L.A.; Sharafuddin, M.J.; Wolverson, M.K.; Heiberg, E.V.; Wade, T.P.; Shields, J.B. Sonographic diagnosis of unsuspected gallbladder cancer: Imaging findings in comparison with benign gallbladder conditions. Am. J. Roentgenol. 1995, 165, 1169-1174. [CrossRef]

62. Xu, J.M.; Guo, L.H.; Xu, H.X.; Zheng, S.G.; Liu, L.N.; Sun, L.P.; Lu, M.D.; Xie, X.Y.; Wang, W.P.; Hu, B.; et al. Differential diagnosis of gallbladder wall thickening: The usefulness of contrast-enhanced ultrasound. Ultrasound Med. Biol. 2014, 40, $2794-2804$. [CrossRef]

63. Tsuchida, A.; Itoi, T.; Endo, M.; Kitamura, K.; Mukaide, M.; Itokawa, F.; Ozawa, T.; Aoki, T. Pathological features and surgical outcome of pancreaticobiliary maljunction without dilatation of the extrahepatic bile duct. Oncol. Rep. 2004, 11, 269-276. [CrossRef]

64. Tanno, S.; Obara, T.; Fujii, T.; Mizukami, Y.; Shudo, R.; Nishino, N.; Ura, H.; Klein-Szanto, A.J.; Kohgo, Y. Proliferative potential and K-ras mutation in epithelial hyperplasia of the gallbladder in patients with anomalous pancreaticobiliary ductal union. Cancer 1998, 83, 267-275. [CrossRef]

65. Takuma, K.; Kamisawa, T.; Tabata, T.; Hara, S.; Kuruma, S.; Inaba, Y.; Kurata, M.; Honda, G.; Tsuruta, K.; Horiguchi, S.; et al. Importance of early diagnosis of pancreaticobiliary maljunction without biliary dilatation. World J. Gastroenterol. 2012, 18, 3409-3414. [CrossRef]

66. Marchal, G.J.; Casaer, M.; Baert, A.L.; Goddeeris, P.G.; Kerremans, R.; Fevery, J. Gallbladder wall sonolucency in acute cholecystitis. Radiology 1979, 133, 429-433. [CrossRef] [PubMed]

67. Päivänsalo, M.; Siniluoto, T.; Myllylä, V.; Kairaluoma, M.I.; Kallioinen, M. Ultrasound in acute and chronic cholecystitis. Rofo 1987, 147, 84-87. [CrossRef] [PubMed] 
68. Cohan, R.H.; Mahony, B.S.; Bowie, J.D.; Cooper, C.; Baker, M.E.; Illescas, F.F. Striated intramural gallbladder lucencies on US studies: Predictors of acute cholecystitis. Radiology 1987, 164, 31-35. [CrossRef]

69. Suk, K.T.; Kim, C.H.; Baik, S.K.; Kim, M.K.; Park, D.H.; Kim, K.H.; Kim, J.W.; Kim, H.S.; Kwon, S.O.; Lee, D.K.; et al. Gallbladder wall thickening in patients with acute hepatitis. J. Clin. Ultrasound 2009, 37, 144-148. [CrossRef]

70. Nabatame, N.; Shirai, Y.; Nishimura, A.; Yokoyama, N.; Wakai, T.; Hatakeyama, K. High risk of gallbladder carcinoma in elderly patients with segmental adenomyomatosis of the gallbladder. J. Exp. Clin. Cancer Res. 2004, 23, 593-598.

71. Ootani, T.; Shirai, Y.; Tsukada, K.; Muto, T. Relationship between gallbladder carcinoma and the segmental type of adenomyomatosis of the gallbladder. Cancer 1992, 69, 2647-2652. [CrossRef]

72. Parra, J.A.; Acinas, O.; Bueno, J.; Güezmes, A.; Fernández, M.A.; Fariñas, M.C. Xanthogranulomatous cholecystitis: Clinical, sonographic, and CT findings in 26 patients. Am. J. Roentgenol. 2000, 174, 979-983. [CrossRef]

73. Goodman, Z.D.; Ishak, K.G. Xanthogranulomatous cholecystitis. Am. J. Surg. Pathol. 1981, 5, 653-659. [CrossRef] [PubMed]

74. Dong, Y.; Xu, B.; Cao, Q.; Zhang, Q.; Qiu, Y.; Yang, D.; Yu, L.; Wang, W.P. Incidentally detected focal fundal gallbladder wall thickening: Differentiation contrast enhanced ultrasound features with high-resolution linear transducers. Clin. Hemorheol. Microcirc. 2020, 74, 315-325. [CrossRef] [PubMed]

75. Nishimura, A.; Shirai, Y.; Hatakeyama, K. Segmental adenomyomatosis of the gallbladder predisposes to cholecystolithiasis. J. Hepatobiliary Pancreat. Surg. 2004, 11, 342-347. [CrossRef] [PubMed]

76. Schiller, V.L.; Turner, R.R.; Sarti, D.A. Color Doppler imaging of the gallbladder wall in acute cholecystitis: Sonographic-pathologic correlation. Abdom. Imaging 1996, 21, 233-237. [CrossRef] [PubMed]

77. Kawashima, H.; Hirooka, Y.; Itoh, A.; Hashimoto, S.; Itoh, I.; Hara, K.; Kanamori, A.; Ohmiya, N.; Niwa, Y.; Goto, H. Use of color Doppler ultrasonography in the diagnosis of anomalous connection in pancreatobiliary disease. World J. Gastroenterol. 2005, 11, 1018-1022. [CrossRef] [PubMed] 